\title{
COLLECTIVE FLEXIBILITY DURING MASS \\ RECRUITMENT IN THE ANT MYRMICA SABULETI \\ (HYMENOPTERA: FORMICIDAE)
}

By J. C. De Biseau ${ }^{1}$, J. L. Deneubourg ${ }^{2}$ and J. M. Pasteels ${ }^{1}$

\section{INTRODUCTION}

If the food recruitment may be considered as a process permitting a quick and efficient exploitation of large food sources, it is also the touchstone of the collective decisions taken by the colonies (Pasteels et al., 1987; Beckers et al., 1990; Camazine \& Sneyd, 1991; Seeley et al., 1991). In a comparative study of several species of ants, Beckers et al. (1990) suggested that the ability of the colonies to direct their foraging activity as a function of the opportunities offered by the environment is correlated to the type of recruitment. When a $1 \mathrm{M}$ sucrose source is introduced into the trophic area of a colony exploiting a $0.1 \mathrm{M}$ or a $0.5 \mathrm{M}$ sucrose source, Tetramorium caespitum (which practices group-mass recruitment) rapidly shifts its activity toward the richer source. By contrast, in the same conditions, Lasius niger (which uses mass recruitment) keeps its first choice. The mechanisms of the recruitment could be at the origin of this difference. The collective flexibility of $T$. caespitum can be explained by two characteristics of its recruitment strategy. The existence of the groups, and in particular the action of the leaders, at the beginning of the recruitment toward a newly discovered source, gives the system a larger independence from the pre-existing chemical information-owing to its individual memory, the leader is able to guide a group of recruits toward new food source without paying attention to the chemical trail leading to another source. In addition, the workers are able to modulate the quantity of pheromone laid, in relation to the concentration of the source (Verhaeghe, 1982). These two mechanisms act together when a new source is discovered while another one is

\footnotetext{
${ }^{1}$ Laboratoire de Biologie Animale et Cellulaire, cp 160/12 - Université Libre de Bruxelles - 50, av. F. Roosevelt - 1050 Bruxelles - Belgium.

${ }^{2}$ Service de Chimie Physique, CP 231 - Université Libre de Bruxelles - Boulevard du Triomphe - 1050 Bruxelles - Belgium Manuscript received 7 February 1992.
} 
already exploited : firstly the leaders and their groups give a chance to any newly discovered source; secondly the modulation of the trail pheromone allows the shift of the global activity if the new source is richer. By contrast, in mass recruitment, the recruited ants have only chemical information to find the food. In such a case, when the colony has started to exploit one source, the recruits could be "trapped" by the already established trail until it fades, at the end of the recruitment.

This paper presents a set of collective choice experiments (very similar to those presented by Beckers et al., 1990) realized on another species, Myrmica sabuleti. After finding food, the recruiters of this species lay a trail pheromone emitted from their poison gland. This pheromone is laid from the food to the nest and from the nest to the food. In addition, the recruiters deposit an attractive and volatile Dufour's gland secretion when going back to the food, but only near the nest entrance ( 2 to $3 \mathrm{~cm}$ ) (Cammaerts \& Cammaerts, 1980). The first purpose of the present work was to verify if Myrmica sabuleti is able to modulate its recruitment rate according to the quality of food, like Tetramorium caespitum. Our second purpose was to test the hypothesis that neither the presence of a group leader nor new directional cues provided by the deposition of pheromone spots near the nest entrance are necessary to obtain a flexibility of collective behavior during recruitments. A mathematical model is then presented, illustrating how a mere modulation of the recruitment rate is sufficient to allow a shift toward a richer source discovered after a poor one, without the recruits being directed by a leader or a different pheromone.

\section{Materials AND Methods}

Outside experimental periods, Myrmica sabuleti societies were supplied with a $0.5 \mathrm{M}$ sucrose solution and a water distributor. Every week, they received dead cockroaches. Colonies were deprived from any food four days before each experiment.

Two experimental setups were used. In the first one, the colony was placed in a $80 \times 80 \mathrm{~cm}$ area. In the second setup, a Y-shaped bridge was placed in front of the nest entrance (the two branches of the $\mathrm{Y}$ are separated by an angle of $60^{\circ}$; the three branches of the bridge were $12 \mathrm{~cm}$ long and $1 \mathrm{~cm}$ wide). By bringing the point of the binary choice $12 \mathrm{~cm}$ from the nest entrance, the possible 
directional effect of the Dufour's gland secretion emitted only 2 or $3 \mathrm{~cm}$ away from the nest entrance (Cammaerts \& Cammaerts, 1980) is eliminated.

A set of experiments with a single source was performed in the first experimental setup. The source $(\mathrm{a} 1 \mathrm{M}, 0.5 \mathrm{M}$ or $0.1 \mathrm{M}$ solution of sucrose) was introduced $40 \mathrm{~cm}$ of the nest entrance. In each experiment performed with a $1 \mathrm{M}$ source, the first recruiter was individually marked with a dot of paint when feeding at the source.

Experiments with two sources were realized in both experimental setups. As in the other experiments, the food sources were solutions of sucrose of a given concentration. In the first setup, the sources were introduced $40 \mathrm{~cm}$ apart and both $40 \mathrm{~cm}$ from the nest entrance. The two sources were placed simultaneously or one after the other. In this latter case, the second source was introduced when the recruitment toward the first one was well initiated (i.e., when 20 to 40 workers were feeding together at the first source). In the second experimental setup, the sources were placed at the end of the 2 branches of the $\mathrm{Y}$ bridge and always introduced one after the other.

The number of ants feeding together at the source(s) was noted every minute until the end of the recruitment. Except when otherwise specified, each experiment was repeated three times with a minimum of two different colonies.

\section{RESULTS}

\section{Single Source Experiments.}

The return of the first recruiter to the nest was generally followed by a massive departure of recruited workers that made their way toward the food, allowing no doubt about the existence of a chemical trail. The intensity of the recruitment is a function of the sucrose concentration (figure 1). The maximum number and the mean number of workers feeding together at the source declined with decreasing concentrations of sucrose, demonstrating that the ants are able to modulate their recruitment rate according to food quality. The presence of the recruiter was not necessary for the orientation of the recruits. Marking experiments showed that in 4 cases out of 6 , the recruiter came back to the source after the recruited workers had reached it. Moreover, in these 4 experiments, the efficiency of the recruitment ( $\%$ of recruited ants 


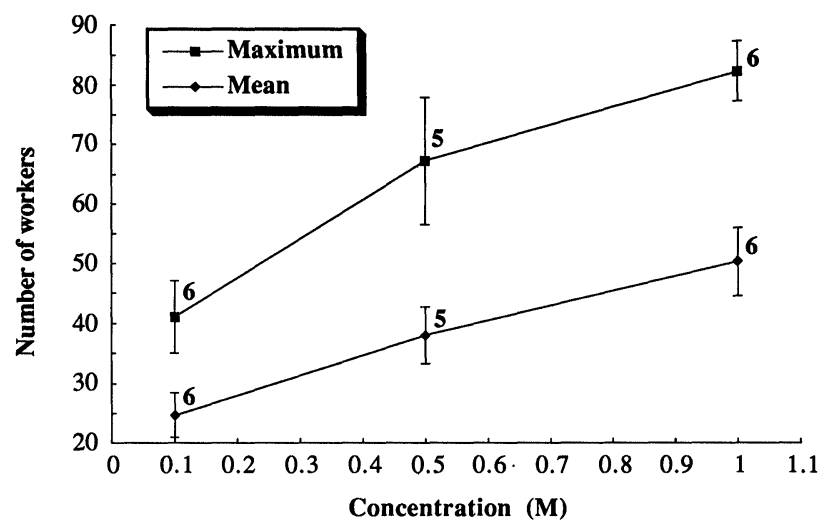

Figure 1. Intensity of the recruitment tor ditterent concentrations in sucrose : means and standard errors. The number near each point is the number of replicates. Mann-Whitney test : for the two curves (maximum number and mean number) the difference is significant $(\mathrm{P}<0.01)$ only between $0.1 \mathrm{M}$ and $1 \mathrm{M}$ sources.

reaching the food source) was respectively $54 \%, 100 \%, 100 \%$ and $75 \%$. Consequently, $M$. sabuleti practices a recruitment without leader, as $L$. niger does.

\section{Two-source experiments.}

For each experiment described here, when the replicates yielded the same qualitative results, only one graph (chosen at random) is presented.

The graph of figure $2 \mathrm{a}$ shows that if a $0.1 \mathrm{M}$ and a $1 \mathrm{M}$ sucrose source were introduced simultaneously on the foraging area, the activity of the colony rapidly concentrated on the richer one. Such a result was also obtained when the poorer source was a $0.5 \mathrm{M}$ sucrose (figure 2b). These results confirm that Myrmica sabuleti is able to modulate the chemical information transmitted as a function of the concentration of the food (for $1 \mathrm{M}, 0.5 \mathrm{M}$ and $0.1 \mathrm{M}$ solutions of sucrose). When a $1 \mathrm{M}$ source was offered after a $0.1 \mathrm{M}$ one, the societies rapidly shifted their activity toward the richer source in all the replicates of the two experimental setups (figure $2 \mathrm{c}$ ). The fact that both experimental setups gave the same results eliminates the possible role of the Dufour's gland secretion on the collective choices made by the colonies. When a $1 \mathrm{M}$ source was offered after a $0.5 \mathrm{M}$ one, the societies stayed with their first choice in the 3 replicates of the first experimental setup and in one replicate of the 
second experimental setup (figure $2 \mathrm{~d}$ and $2 \mathrm{e}$ ) but a shift of activity was obtained in two replicates of the second experimental setup (figure 2f). Nevertheless, the time of shift (defined as the lapse of time separating the discovery of the $1 \mathrm{M}$ source and the moment where the population at this source was $\geq 50 \%$ ) was always shorter when the poorer source was a $0.1 \mathrm{M}$ one $(9.7 \pm 1.4 \mathrm{~min}$.) than when it was a $0.5 \mathrm{M}$ one (respectively 22 and 26 minutes for the two shifts obtained). When there was no difference between the two sources, the global activity always stayed on the first source introduced (figure $2 \mathrm{~g}$ ).

\section{Mathematical Modeling of Collective Choices}

\section{Model of recruitment and trail following.}

Only mathematic tools can explain rigorously the transition between individual and collective behavior. The mathematical model we use here (Pasteels et al., 1987; Beckers et al., 1990) is based upon simple rules. At a time $t$ of the recruitment in progress toward a source $i$, the $N$ foragers of the colony may be subdivided into three groups : $E$, the number of workers exploring the foraging area; $X i$, the number of workers feeding at source $i$ and $N-E-\Sigma X i$, the number of foragers waiting in the nest. At any time, the outgoing flow at the nest is a function of the recruitment rate $\left(a_{\mathrm{i}}\right)$, the number of foragers in the nest and the number of recruiters involved in the foraging process. Of these recruits, only a fraction (Fi) reach the food. The others $(1-F i)$ lose the trail and become explorers. These explorers may go back to the nest after a search time $(1 / p)$ or discover the source by chance (with a probability $c$ ). If the mean residence time at the source is $1 / b$, we have :

$$
\begin{aligned}
& \frac{d X_{i}}{d t}=a_{i} X_{i}\left(N-E-\sum_{i=1}^{n} X_{i}\right) F_{i}+c E b X_{i} \\
& \frac{d E}{d t}=a_{i} X_{i}\left(N-E-\sum_{i=1}^{n} X_{i}\right)\left(1-F_{i}\right)-n c E-p E
\end{aligned}
$$

where $n$ is the number of food sources.

During typical mass recruitment, the recruited ants reinforce the trail (see for example Sudd, 1960; Wilson, 1962). In such a situation, the efficiency of the recruitment increases with the number of 

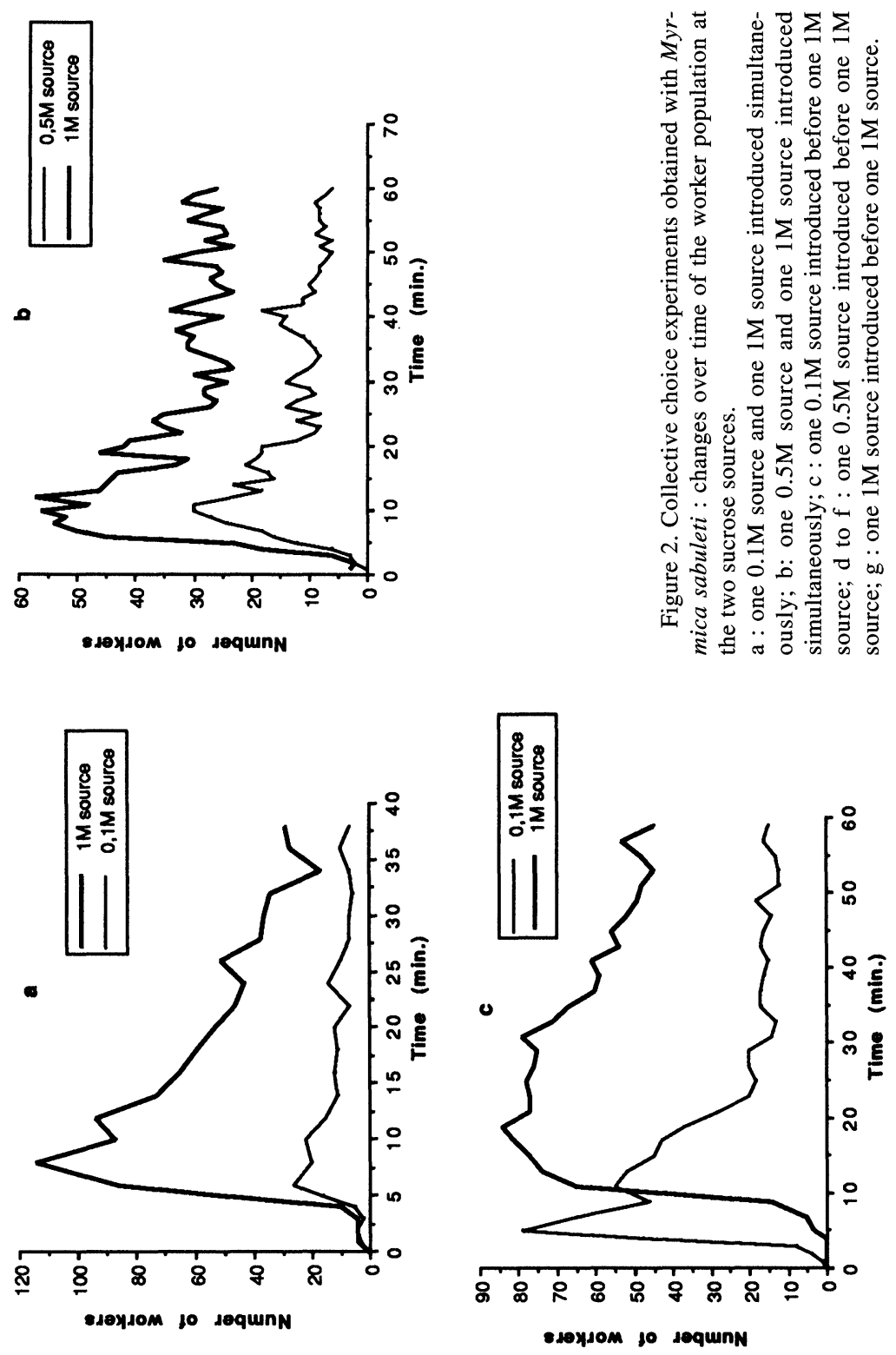

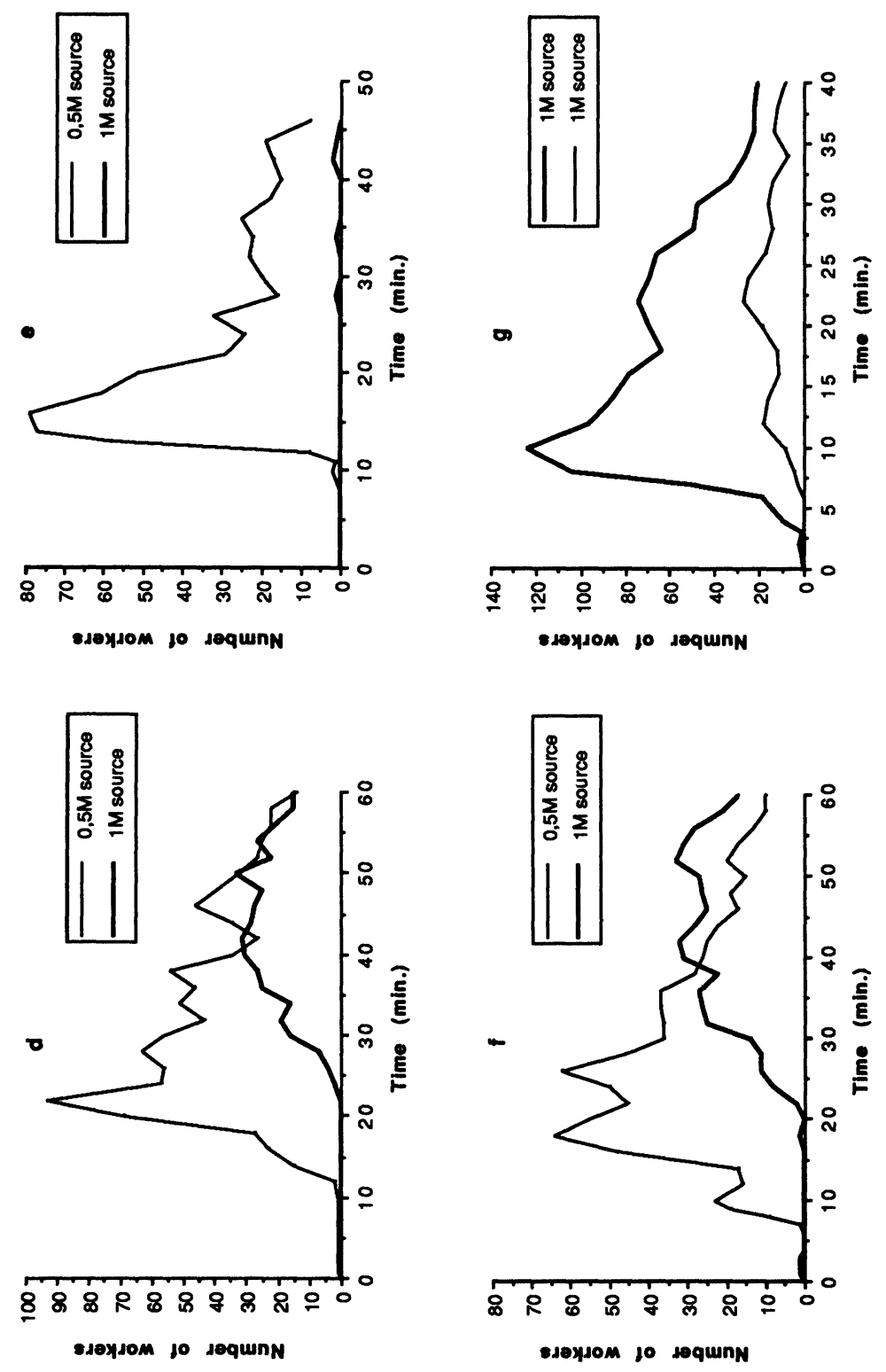
recruiters. Consequently, $F i$ may be represented as a function of $X i$ :

$$
F_{i}=\frac{g_{i}+x_{i}^{2}}{h_{i}+x_{i}^{2}}
$$

where $g_{i}$ and $h_{i}$ are constants characterizing the efficiency of the trail at the beginning of the recruitment $\left(\mathrm{g}_{\mathrm{i}} \geq \mathrm{h}_{\mathrm{i}}\right)$.

Modulation of transmitted information.

By modifying the parameters $a_{\mathrm{i}}$ and $F i$ in the mathematical model, the modulation of information may be reproduced. For a richer source, $a_{\mathrm{i}}$ and $F i$ (or more precisely the ratio $\mathrm{g}_{\mathrm{i}} / \mathrm{h}_{\mathrm{i}}$ ) should be greater than for a poor one : $a_{\mathrm{i}}$ is greater because we assume that the rate of the recruitment increases with the quality of food and $\mathrm{g}_{\mathrm{i}} / \mathrm{h}_{\mathrm{i}}$ is greater because we assume that the ants trail more and thus

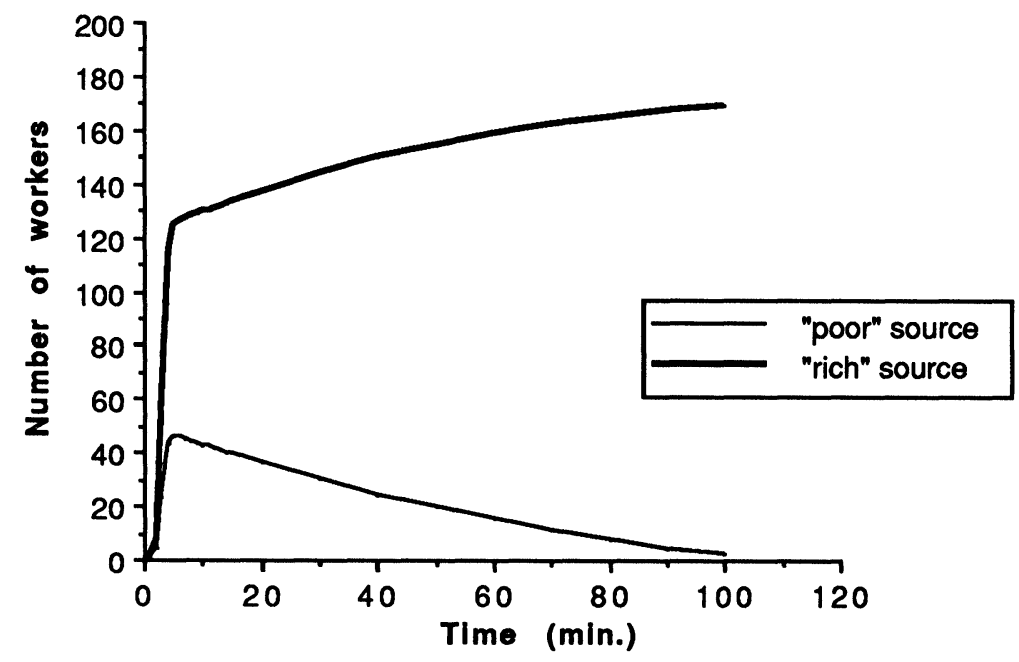

Figure 3. Theoretical simulations : changes over time of the worker population at two sucrose sources introduced simultaneously.

$\mathrm{N}=200 ; \mathrm{b}=0.33 ; \mathrm{c}=0.02 ; \mathrm{p}=0.001 ; \mathrm{a}_{1}=0.014 ; \mathrm{a}_{2}=0.015 ; \mathrm{F}_{1}=\frac{15+\mathrm{X}^{2}}{25+\mathrm{X}^{2}} ;$ $F_{2}=\frac{15+X^{2}}{20+X^{2}}$ 
that less recruits lose the trail. The simulation of figure 3 shows that a small difference of $a_{\mathrm{i}}$ and $F i$ leads to the selection of the rich source when two sources of different quality are offered simultaneously, owing to the amplifying nature of the recruitment. This collective decision results from a competition between two autocatalytic processes with different increasing speeds (Pasteels et al., 1987).

It is upon the same modulation mechanism that we base our explanation of the ability or inability of the colonies to shift their foraging activity on a source when a poorer one is already exploited. Our assumption is presented in figure 4. The curve $a$ describes the capacity of modulation of a first theoretical species $A$ in which the difference of pheromone quantity emitted during the exploitation of a $0.1 \mathrm{M}$ and a $1 \mathrm{M}$ source is small. If these two sources are discovered at the same time, this difference is sufficient to give advantage to the exploitation of the richer one. By

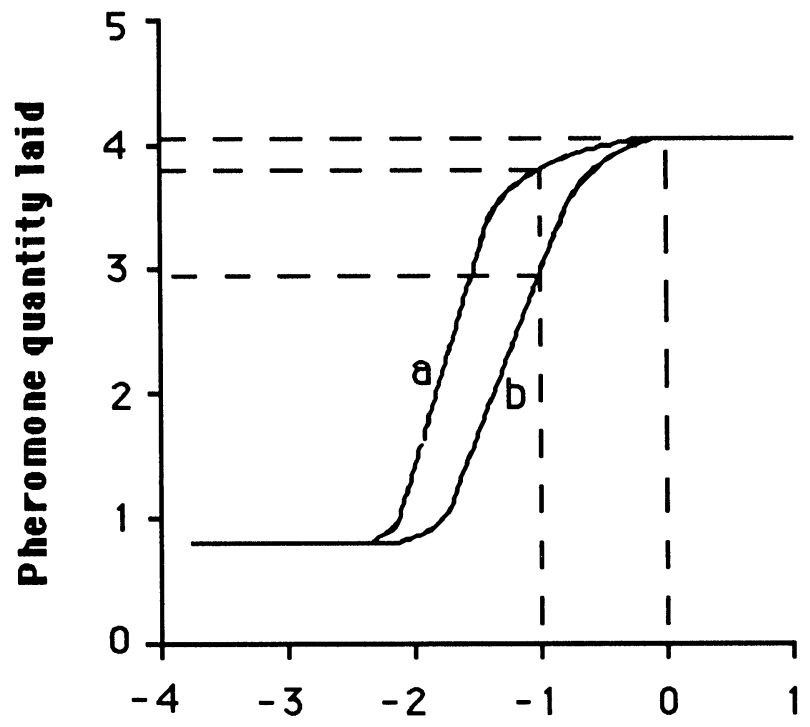

Logarithm of the concentration of the source

Figure 4. Modulation of the trail pheromone quantity emitted as a function of the concentration of the sucrose source (hypothetical curves).

$\mathrm{a}:$ theoretical species $A ; \mathrm{b}$ : theoretical species $B$. 
contrast, if the trail leading to the poor source has been already reinforced, even slightly, this difference would not be sufficient to allow the change of the colony's foraging activity to the richer source discovered later. The system thus stays with its first choice. The curve $b$ describes the capacity of modulation of a second theoretical species $B$. The difference of pheromone quantity emitted for a $0.1 \mathrm{M}$ and a $1 \mathrm{M}$ source is greater and allows the shift towards the richer source even when discovered while a less rewarding one is already exploited. However the difference is too weak to allow the selection of a $1 \mathrm{M}$ source discovered after a $0.5 \mathrm{M}$ one.

The simulations of figure 5 show that the collective behavior of $M$. sabuleti can be reproduced with the assumption that the modulation of chemical information in function of food quality is similar to that described in figure 4 (curve b). When the difference of pheromone quantity emitted is large (i.e. in the $0.1 \mathrm{M}$ vs $1 \mathrm{M}$ experiments), the activity of the colony rapidly shifts towards the richer source (figure $5 \mathrm{a})$. If this difference is small $(0.5 \mathrm{M}$ vs $1 \mathrm{M})$, the colony generally stays with its first choice (figure $5 \mathrm{~b}$ ).

\section{DISCUSSION}

Our experiments demonstrated that $M$. sabuleti (like other ants : Hantgartner, 1969, 1970; Cammaerts, 1977; Verhaeghe, 1982) is able to modulate its recruitment efficiency according to food quality. This allows the ants to exploit a rich source more intensely than a poor one, to select the richer source out of two simultaneous sources and, to some extent, to shift their foraging activity toward a richer source discovered while another one is already exploited. This shift of activity does not necessitate a leader able to guide the ants toward the second source, contrary to previous suggestions (Beckers et al., 1990).

Cammaerts and Cammaerts (1980) reported that during food recruitment $M$. sabuleti lay their attractive Dufour's gland secretion close to the nest entrance. Their evidence, however, is indirect, based on the morphology of ant tracks left on smoked glass and a comparison with $M$. rubra. Even if confirmed, the deposition of attractive pheromone on a short distance from the nest toward the food does not convey the directional cues allowing the ants to shift their activity. The deposition of Dufour's gland secretion, 

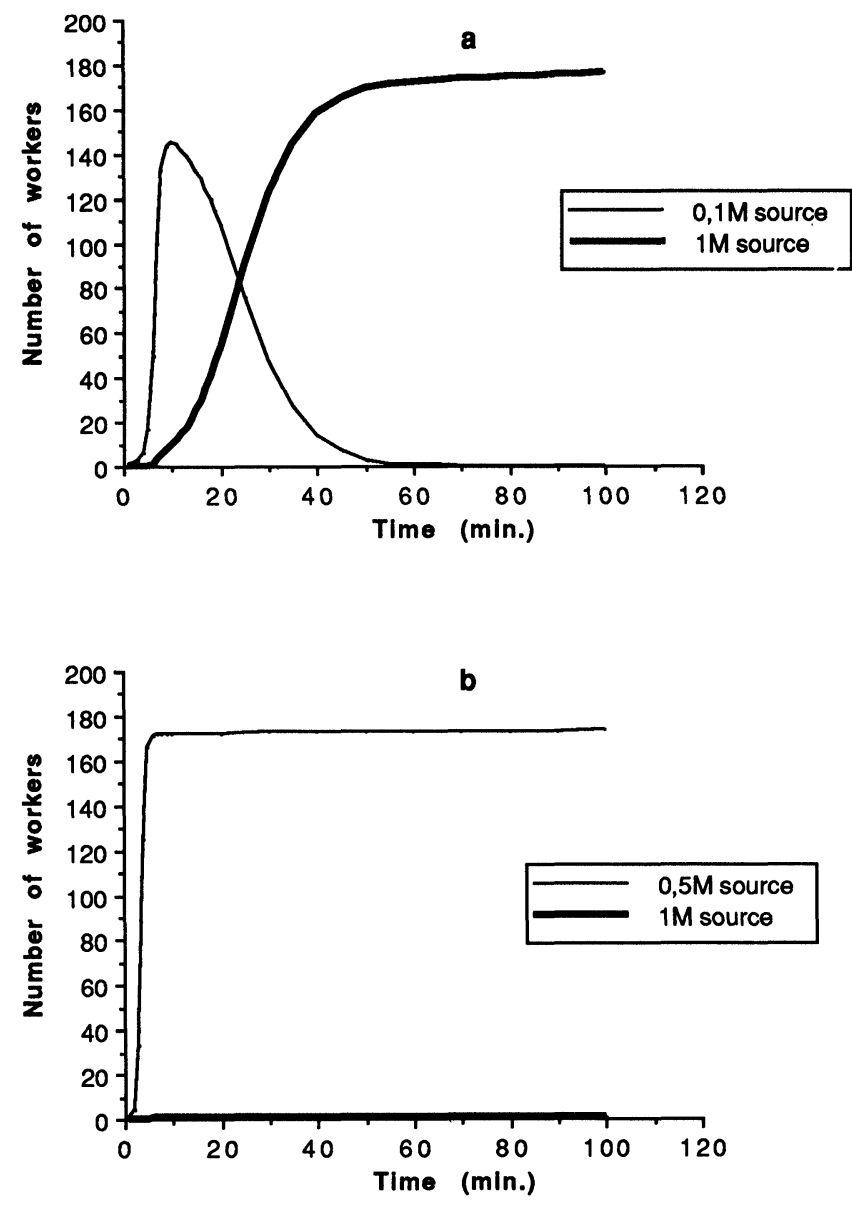

Figure 5. Theoretical simulations : changes over time of the worker population at two sucrose sources $(0.1 \mathrm{M}$ or $0.5 \mathrm{M}$ introduced before $1 \mathrm{M})$.

$\mathrm{a}:$ large difference of the pheromone quantity laid for the two sources : $\mathrm{a}_{1}=0.009$; $\mathrm{a}_{2}=0.014$

$$
F_{1}=\frac{15+X^{2}}{35+X^{2}} ; F_{2}=\frac{15+X^{2}}{20+X^{2}}
$$

$\mathrm{b}$ : small difference of the pheromone quantity laid for the two sources : $\mathrm{a}_{1}=0.014$; $\mathrm{a}_{2}=0.015$

$$
F_{1}=\frac{15+X^{2}}{25+X^{2}} ; F_{2}=\frac{15+X^{2}}{20+X^{2}}
$$


however, could be important by inducing more ants to leave the nest.

The model confirms that no leader is needed to induce shifts of activity, but that a modulation of the transmitted information can be sufficient. The modulation of information in the model involves two parameters, the number of ants induced to leave the nest $\left(a_{\mathrm{i}}\right)$ and the trail-following efficiency $\left(\mathrm{g}_{\mathrm{i}} / \mathrm{h}_{\mathrm{i}}\right)$. Although the modulation of the secretion of a single signal (i.e. the trail pheromone) could possibly influence both parameters, ants often use different signals during food recruitment (e.g. invitation behavior and/or multicomponent trail pheromone : Cammaerts-Tricot, 1974; Hölldobler, 1982a, 1982b; Van der Meer et al., 1988, 1990). We do not know yet whether or not $M$. sabuleti uses several signals and how they are modulated. Although flexibility can be reached by the modulation of a single chemical signal, a process based on several signals seems intuitively more reliable than one based on a single one. The modulation of a single signal needs to be precisely tuned to allow a flexible foraging behavior : this is not easy to achieve when the signal (i.e., the trail pheromone) is laid on a heterogeneous substrate with variable adsorption properties. Group leading could add to the accuracy of the process, but it is not necessary to obtain a flexible behavior.

Undoubtedly, there are many ways for ant colonies to achieve flexibility in their recruitments. The real challenge is now to understand if and how some ways are better adapted than others to particular ecological conditions.

At first glance, the rigid behavior of $L$. niger (Beckers et al., 1990) may seem under-optimal compared to that of M. sabuleti. However, all the experiments discussed here were realized in an ideal environment, without competitors. We can image two very different strategies to face competition in nature. Firstly, the colony may stake on a mass strategy, involving the mobilization of a large number of individuals which exploit, but also defend the source to secure its total control. In such a strategy, the colony takes the decision to invest the bulk of its activity in the exploitation of one source sufficiently rewarding and hold on until its exhaustion. Secondly, the colony may stake on a more opportunistic strategy, preferring to shift its main activity rather than to defend the source "against all comers". This second strategy 
requires a flexibility and a swiftness that the first one does not involve. The study of the effect of competition upon the collective decisions of $M$. sabuleti is one of our present objectives.

\section{SUMMARY}

This paper describes the recruitment strategy of the ant Myrmica sabuleti and the collective behavior of the colonies when two sources of sucrose are offered. Our experiments show that this species uses an explosive mass recruitment to exploit large sources. A colony is able to select the richer source out of two simultaneously offered ones and, to some extent, to shift its main foraging activity toward a richer source discovered after a poor one. The role of the modulation of the chemical signals on the collective decisions is analyzed with the help of a mathematical model of recruitment and trail following. Our results are compared to those obtained with two other species. They suggest that modulating the deposition of the trail pheromone is sufficient to obtain a collective flexibility during mass recruitments.

\section{ACKNOWLEDGEMENTS}

This research was supported by a fellowship from the Belgian I.R.S.I.A $\mathrm{n}^{\mathrm{O}}$ 890674, the Venture Research Unit of British Petroleum and the Erna och Victor Hasselbladt Foundation. We would like to thank Dr. Y. Roisin for critical comments and English corrections and D. Vanhauwermeiren for her help in the realisation of the experiments. J. L. Deneubourg is a fellow of the Belgian "Fonds National de la Recherche Scientifique."

\section{REFERENCES}

Beckers, R., Deneubourg, J. L., Goss, S., and Pasteels, J. M.

1990. Collective decision making through food recruitment. Insectes Sociaux, 37(3), 258-267.

CAmmaerts-Tricot, M. C.

1974. Piste et phéromone attractive chez la fourmi Myrmica rubra. J. Comp. Physiol., 88(4), 373-832.

Cammaerts, M. C.

1977. Recruitment to food in Myrmica rubra L. Proc 8th Int. Congr. IUSSI, Wageningen, 294.

CAMmaerts, M.C. AND CAMmaerTs, R.

1980. Food recruitment strategies of the ants Myrmica sabuleti and Myrmica ruginodis. Behavioural Process, 5, 251-270. 
CAmazine, S. ANd SNeYd, J.

1991. A mathematical model of colony level nectar source selection by honey bees : self-organization through simple rules. J. Theor. Biol., 149, 547-571.

HANGARTNER, W.

1969. Structure and variability of the individual odor trail in Solenopsis geminata Fabr. (Hymenoptera, Formicidae). Z. Vergl. Physiologie, 62, 111-120.

1970. Control of pheromone quantity in odor trails of the ant Acanthomyops interjectus Mayr. Separatum Experentia, 26, 664-665.

HÖLLDOBLER, B.

1982a. The cloacal gland, a new pheromone gland in ants. Naturwissenschaften, 69(4), 186-187.

1982b. Communication, raiding behavior and prey storage in Cerapachys (Hymenoptera : Formicidae). Psyche, 89(1-2), 3-23.

Pasteels, J. M., Deneubourg, J. L., And Goss, S.

1987. Self-organization mechanisms in ant societies : trail recruitment to newly discovered food sources. In : From Individual to Collective Behavior in Social Insects, J. M. Pasteels \& J. L. Deneubourg Eds, Birkhäuser, 155-175.

Seeley, T. D., Camazine, S., and Sneyd, J.

1991. Collective decision-making in honeybees : how colonies choose among nectar sources. Behav. Ecol. Sociobiol., 28, 277-290.

SudD, J. H.

1960. The foraging method of Pharaoh's ant, Monomorium pharaonis (L.). Anim. Behav., 8, 67-75.

Van Der Meer, R. K., Alvarez, F. M., AND Lofgren, C. S.

1988. Isolation of the recruitment pheromone of Solenopsis invicta. J. Chem. Ecol., 14, 825-838.

Van Der Meer, R. K., Lofgren, C. S., ANd Alvarez, F. M.

1990. The orientation inducer pheromone of the fire ant Solenopsis invicta. Physiological Entomology, 15, 483-488.

VerhaEghe, J. C.

1982. Food recruitment in Tetramorium impurum (Hymenoptera : Formicidae). Insectes Sociaux, 29, 67-85.

WILSON, E. O.

1962. Chemical communication among workers of the fire ant Solenopsis saevissima (Fr. Smith). 1. The organization of mass foraging. Anim. Behav., 10, 134-147. 

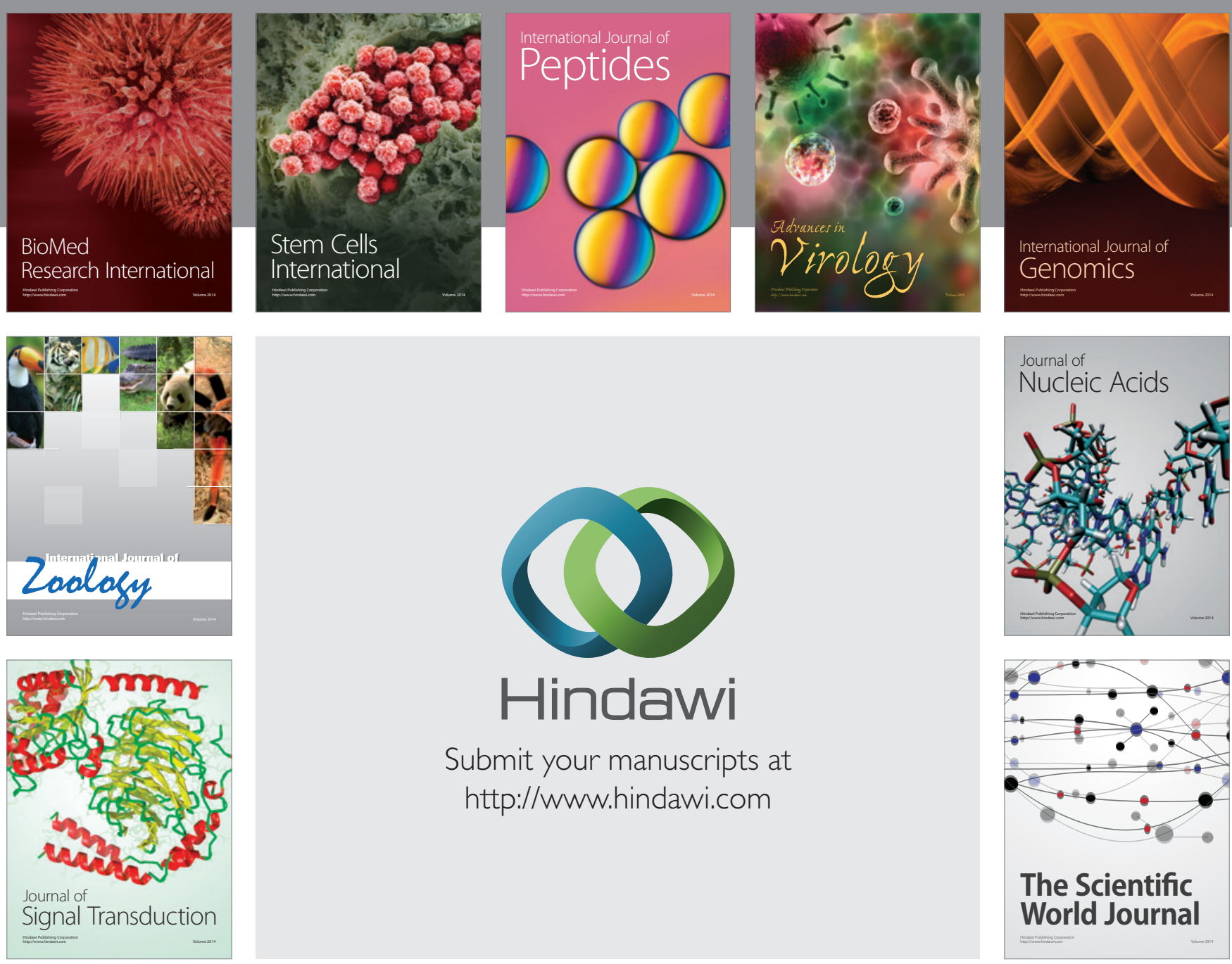

Submit your manuscripts at

http://www.hindawi.com
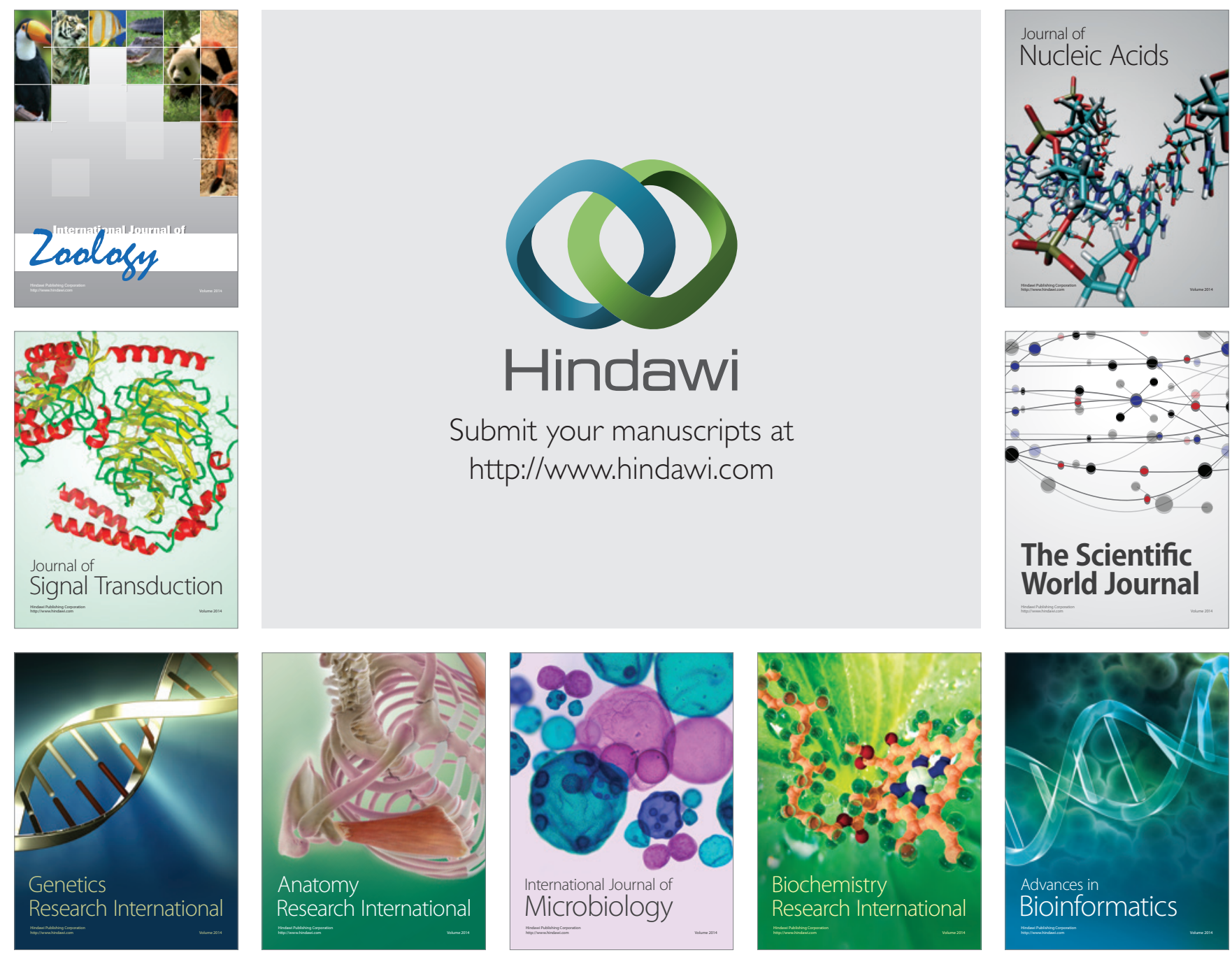

The Scientific World Journal
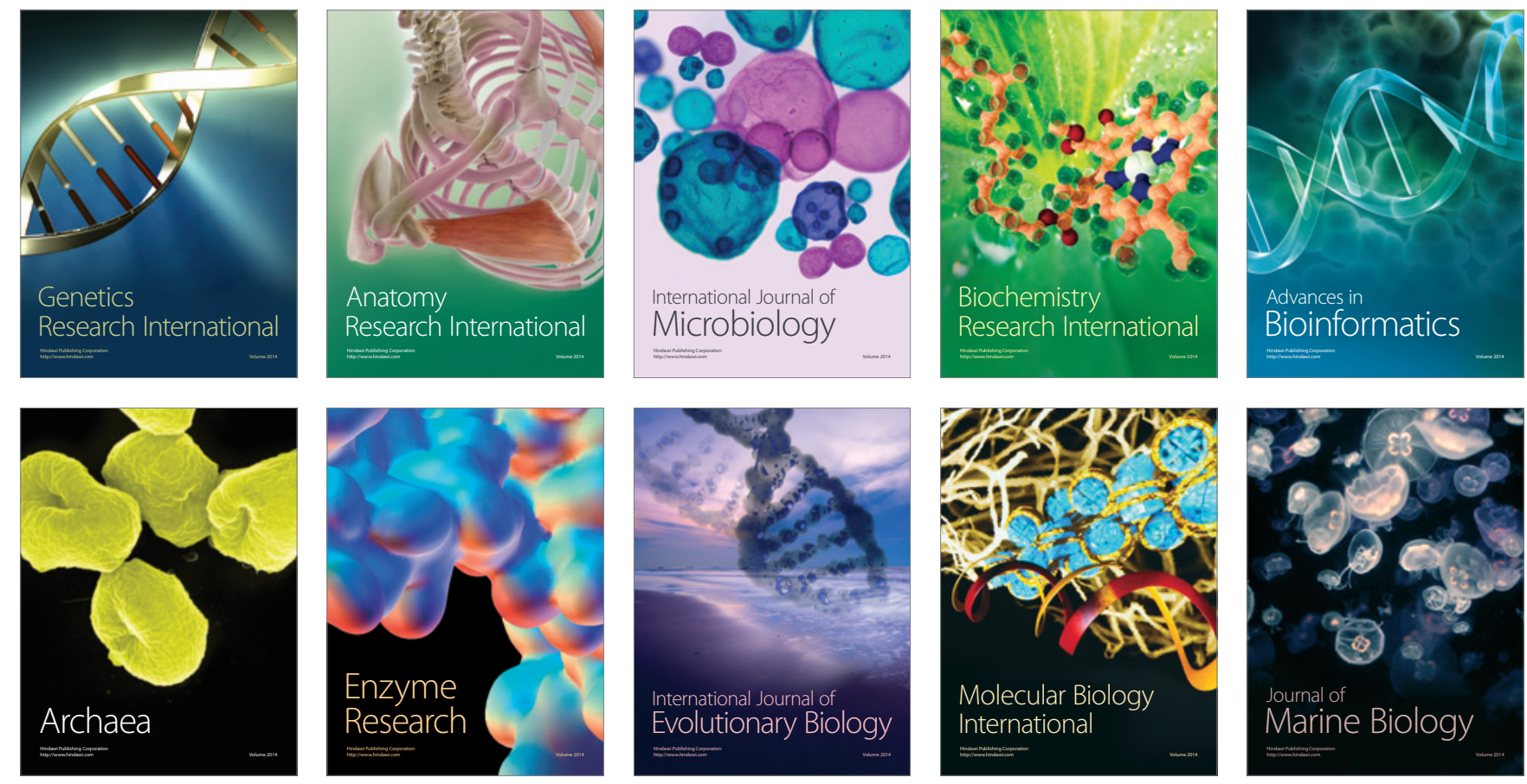